\begin{abstract}
Для цитирования: Забара Л. И. Геополитический имидж России в современном медийном пространстве (международная конференция «Учимся понимать Россию: политическая и массмедийная коммуникация»

10-14 октября, г. Екатеринбург) // Социум и власть. 2018. № 6 (74). С. 117-121.
\end{abstract}

УдК $327.2+366.63$

ГЕОПОЛИТИЧЕСКИЙ ИМИДЖ РОССИИ В СОВРЕМЕННОМ МЕДИЙНОМ ПРОСТРАНСТВЕ (МЕЖДУНАРОДНАЯ КОНФЕРЕНЦИЯ «УЧИМСЯ ПОНИМАТЬ РОССИЮ: ПОЛИТИЧЕСКАЯ И МАССМЕДИЙНАЯ КОММУНИКАЦИЯ» 10-14 октября, г. Екатеринбург) ${ }^{11}$

\author{
Забара Людмила Ивановна, \\ Уральский государственный \\ педагогический университет, доцент, \\ кандидат философских наук. \\ Российская Федерация, \\ 620017, г. Екатеринбург, пр. Космонавтов, д. 26.
} E-mail: rni221@yandex.ru

Аннотация

Статья представляет собой обзор работы круглого стола на тему «Геополитический имидж России», проведенного в рамках Международной научной конференции по политической коммуникации «Учимся понимать Россию: политическая и массмедийная коммуникация».

В статье излагается содержание наиболее значимых докладов и дискуссий, раскрывающих особенности внутренних и внешних факторов, формирующих геополитический имидж России.

Высказывается необходимость конвергентных исследований, создания научных сообществ, позволяющих более глубоко и основательно изучить представленную тему.

Ключевые понятия: геополитический имидж, «глобализация» высшего образования, демографический прогноз, национальная идея, историческая память.

\footnotetext{
Статья подготовлена в рамках проекта № 18012-20083 Российского фонда фундаментальных исследований.
}

«Учимся понимать Россию: политическая и массмедийная коммуникация», - так была определена тема конференции, прошедшей 10-14 октября 2018 г. в Уральском государственном педагогическом университете при поддержке Российского фонда фундаментальных исследований. Это традиционная Международная научная конференция по политической лингвистике, имеющая четырнадцатилетнюю историю.

Традиционно в рамках конференции были организованы научные и научно-популярные лекции, мастер-классы, групповые и индивидуальные консультации профессоров, ведущих специалистов по политической коммуникации, представителей различных научных школ из России и Китая, стран ШОС, стран СНГ, государств Восточной и центральной Европы, США.

В 2018 г. соорганизатором конференции выступил наш давний и надежный партнер Цзилиньский университет иностранных языков «Хуацяо».

О масштабном характере этого знаменательного события говорит разнообразие мероприятий (актовые лекции, мастер-классы, курсы повышения квалификации, «Круглые столы», секционные заседания), прошедших на различных площадках, включая Президентский центр Б. Н. Ельцина.

Прошло два Международных конкурса — «Умом Россию не понять» и конкурс методических разработок по русскому языку как иностранному. Большой интерес участников вызвал мастер-класс «Грантмейкинг: заявка на успех», в рамках которого был представлен грантовый опыт организаторов конференции, рассмотрены возможности создания новых перспективных проектов, отражающих стратегические направления развития научных исследований коллаборационных исследовательских коллективов.

Отличительной особенностью конференции стало широкое привлечение специалистов из самых разных научных направлений психологии, социологии, политологии, культурологии, экономики, философии и др. В рамках круглого стола «Геополитический имидж России» обсуждали проблемы формирования в общественном и индивидуальном сознании внутреннего и внешнего имиджа государства как противоречивого единства устоявшихся, традиционных стереотипов и новых, подверженных непрерывным трансформациям, образах Российского государства.

Во вступительном слове ведущая круглого стола кандидат философских наук, доцент л. И. Забара обратила внимание участников на комплексный характер проблемы, позволяющий объединить усилия различных ученых, представителей социально-гуманитарного знания, в конкретизации наиболее 
актуальных и значимых факторов, формирующих геополитический имидж России. Участникам встречи были предложены следующие вопросы для обсуждения:

- из чего складывается имидж России сегодня?

- на какие процессы внутреннего развития государства следует обратить внимание прежде всего?

- за что критикуют российскую экономику?

- чем отличается демографическая ситуация в нашей стране?

- какие изменения происходят в системе российского образования?

Доктор философских наук, профессор Л. А. Беляева предложила начать с обсуждения последнего вопроса как наиболее актуального для преподавателей высшей школы, находящейся в постоянном процессе модернизации и оптимизации в условиях вызовов рыночной экономики и идеологии. Традиции русского классического образования остались в прошлом. Коммерциализация образования и науки привела к тому, что изменилась концепция знания. Отношение к знанию как к абсолютной ценности, инструменту овладения природой, несущему благо человечеству, сменилось новой ориентацией финансовой эффективности конкретного знания в краткосрочной перспективе. Знание становится товаром, а профессиональное университетское сообщество постигает азы коммерческого менеджмента.

Под влиянием рыночной экономики и порождаемой ею рыночной идеологии как системы ценностных ориентиров, выражающих рыночные интересы, учреждения образования довольно стремительно превращаются в организации по производству и оказанию образовательных услуг. Это в корне меняет характер образовательных отношений, особенно в сфере высшего профессионального образования, которые теперь выглядят принципиально иначе - не взаимоотношения «преподаватель - студент», а отношения «продавца» и «покупателя» образовательных услуг. При этом задача продавца - держать руку на пульсе запросов покупателя и не забывать о конкуренции с другими образовательными организациями.

Превращение университетов в экономические корпорации радикально меняет не только характер учебной деятельности преподавателя, но и характер его научно-исследовательской работы. Он теперь должен быть еще и промоутером, т. е. заниматься продвижением результатов своих исследований в виртуальном и реальном социальном пространствах с целью дивидендов в материальной или символической формах. Новое знание (информация) необходимо не ради истины, а ради нового продаваемого продукта, ради «игры в Хирша», ради инди- видуального и корпоративного имиджа. Научная деятельность преподавателя сегодня основана на симбиозе менеджмента и маркетинга и нацелена на оптимизацию издержек, рационализацию процесса научного производства, сбыта и сопутствующего сервиса, как на уровне отдельного ученого, так и для университетской корпорации в целом.

Таким образом, можно констатировать переход от старой традиции существования в науке, не обремененной гонкой за количеством грантов, публикаций, цитирований и наращиванием рейтингов, к новой парадигме, парадигме предприимчивости и продуктивной активности.

Другой вызов современности - это научно-технический прогресс и грядущая цифровая экономика, которая приобретает глобальный характер. Развитие цифрового производства приведет к кардинальным изменениям на рынке труда, вытеснив человека из многих привычных сфер деятельности.

Цифровая революция несет в себе серьезные и невиданные вызовы высшему образованию, да и всей образовательной системе в целом, прежде всего потому, что потребует радикальных изменений в кадровой структуре общества и в системе требований рынка труда. Радикальные изменения коснутся в первую очередь содержания образования и форм обучения, в том числе с широким использованием цифровых технологий и индивидуально-творческих траекторий обучения. И к этому надо готовиться заблаговременно, подчеркивает автор. «И главное, если считать, что образование исторически возникло из потребности в передаче накопленного социального опыта, культуры от поколения к поколению, то в этом отношении модернизацию российского образования можно рассматривать как форму генной инженерии, в ходе которой исподволь, незаметно происходит замена культургена российской идентичности на гены инокультурного содержания», сделала вывод Л. А. Беляева.

Безусловно, имидж России сегодня невозможно представить без интеграции в мировое образовательное пространство, ответов на вызовы, «глобализацию» высшего образования.

Ставший реальностью феномен информационного потребления видоизменяет значение традиционных форм педагогического взаимодействия, содержание самой педагогической деятельности. Виртуальная реальность занимает значительное место в пространстве педагогического процесса, постепенно превращая образовательное учреждение в подобие диспетчерского информационного центра, вырабатывающего и доставляющего до потребителя информационный продукт.

Вступивший в диалог доктор философских наук, профессор В. Б. Куликов обратил 
внимание слушателей на достаточно противоречивый опыт взаимодействия педагогики и философии, актуальный сегодня, как никогда. На самом деле модернизированный образ педагогики характеризуется погружением в детализацию изменяющихся способов воспитания, в управленческие задачи образовательного процесса, разработку учебных программ, конкретизацию учебно-поисковой деятельности, конструирование инновационных образовательных моделей и в такое разнообразие педагогических технологий, что для современного учителя за этим текущим процессом не прослеживается даже желания задуматься о смысле того, что происходит в его собственной деятельности, в чем истина и цель его ежедневных педагогических усилий.

На фоне происходящих в информационном обществе процессов, когда педагогические акценты смещаются в сферу подготовки и выполнения стандартизированных тестовых заданий, актуально жизненными становятся вопросы философии - кого и как воспитывать, в чем сущность и истина воспитания человека.

Педагогическая реальность призвана обращаться к общим философско-ориентированным вопросам, которые вырывают педагогику из паутины решений конкретных, организационно-методических задач и поднимают до уровня науки. Учитель зависим от массы формальных обстоятельств, но эта зависимость не мешает ему создавать новую реальность, новый взгляд на мир, если учитель ориентирован внутренне на философскую свободу.

Педагогика, прикрываясь универсальными классификациями, собраниями правил и принципов, набором педагогических рецептов и технологий, одновременно остро нуждается в открытом горизонте новых возможностей и перспектив. Философия в условиях замкнутого педагогического пространства и ограниченного времени осуществляет поиск выхода за видимые пределы, предписанными действующими педагогическими стандартами или строго спланированными мероприятиями. Философы понимают, что вопрос о становлении человеческого в человеке не предполагает ответа не в силу недостаточного знания этого процесса, а в силу своей уникальности, неповторимости. Разрастающаяся сумма знаний о человеке не приближает к пониманию человеческой парадоксальности, и в значительной степени упрощает это понимание до уровня причинно-следственных связей.

Философская истина проявляется в педагогической реальности не в возможности универсального ответа на вопросы воспитания, а в способности эти вопросы ставить и обозначать проблемы. Применение мудрости направленно на полноту восприятия и пони- мания сущности человека, способности быть открытым миру и давать возможность миру представлять себя через человека. Только таким образом достигается согласие с миром и понимание мира в себе таковым, каков этот мир есть на самом деле.

Информационный контент отчасти позволяет педагогике закрыться от целого спектра философских вопросов о человеке, чтобы не углубляться в разнообразие метафизических схем и концепций. Одновременно педагогика всегда остро ощущает дефицит фундаментального философского отношения к миру и человеку, которые придают конкретной педагогической деятельности устойчивость и основательность мудрости. Хорошему педагогу в его деятельности важна не только сумма знаний, но стремление постигнуть парадоксальную природу своего ученика, самого себя, да и социума в целом.

Наряду с глубокими философскими выводами В. Б. Куликов высказал достаточно оптимистичное и вдохновляющее предположение, что философия, по существу, оказывается единственной альтернативой для спасения от формализма бесконечного совершенствования учебно-методических комплексов и быстро сменяющихся форм отчетности. Поднять голову в поиске философских истин следует ради сохранения чистых помыслов творческого общения с учениками вопреки всем условиям формального закрепощения педагогической деятельности.

Так и хочется сказать: «Лучшие педагоги - философы, а лучшие философы - педагоги!».

Выступление В. Б. Куликова поставило серьезные вопросы о новых моделях педагогической деятельности, организации современного образовательного пространства в новом глобализованном мире, и роль философии в этом процессе трудно переоценить.

Пытаясь осмыслить внутренние и внешние факторы, формирующие геополитический имидж России, обратимся к анализу современной демографический и экономической ситуации. Известный российский демограф, доктор социологических наук, профессор А. И. Кузьмин обозначил следующие актуальные проблемы:

1. Депопуляция населения. Это сокращение пополнения населения из «внутренних источников». Демографическая ситуация ухудшается по показателям естественного прироста. Главные причины - уменьшение числа россиян детородного возраста, снижение потребности в детях и непростые экономические условия. Если в советское время в Свердловской области проживало около пяти миллионов человек, то сейчас 4 млн 325 тыс., и этот процесс продолжается. Причем свердловчан становится меньше прежде всего за счет спада рождаемости. 
За 2017 г. на Среднем Урале родилось на 11 \% меньше детей, чем в 2016, - и такая тенденция характерна для всей страны. По показателям зачастую бьет и младенческая смертность - тревожная статистика, например, в городе Волчанске Свердловской области. Ситуация в целом по области такова: в прошлом году на 13,4% снизилось число родившихся по сравнению с благополучным 2014 г. Получается, мы «потеряли» 15 детей из каждых 100, несмотря на то что государство поощряло высокую рождаемость: материнский капитал продолжал работать.

2. Миграционная активность. Эта тема актуальна для Европы, России и даже нашего региона. Так, в 2017 г. сменить место жительства внутри региона решили более 70 тыс. жителей. Это очень много, ведь так называемая «оптимальная» миграция составляет у нас около трех тысяч человек.

3. Внебрачная рождаемость. Среднее число детей в гражданском браке намного меньше, чем в официальном (это данные Росстата). А между динамикой показателей «брачности» и рождаемости существует сильная корреляционная связь. Вывод - демографическая политика должна быть направлена на увеличение числа новых законных браков, недостаточно стимулировать рождение детей в уже существующих супружеских парах. Кстати, изменился возраст рождения первого ребенка. Раньше он составлял 22 года, сейчас - 31 год. Стали чаще рожать женщины за 30 и даже за 40 лет. Это тоже тенденция. Хотя общая установка на малодетность доминирует. Нужна новая цель среднедетная семья.

4. Продолжительность жизни россиян. Она зависит от многих факторов. Например, от реальной программы жизни, от уровня развития так называемого «самосохранительного» поведения. Увы, у нас оно, в отличие от репродуктивного, пока по-настоящему не изучается, ограничивается только пропагандой здорового и спортивного образа жизни. Сегодня в России средняя продолжительность жизни составляет 70 лет, в Екатеринбурге этот показатель для лиц обоего пола - 73,42 года. Женщины живут у нас в среднем 78,4 года, мужчины на 10 лет меньше - 68,4. Продолжительность жизни в глубинке меньше, чем в Екатеринбурге, на четыре года.

И наконец, рассмотрим демографический прогноз, который имеет непосредственное отношение к геополитическому имиджу России. Как изменится численность населения? Сколько россиян будет жить, к примеру, через 18 лет?

Росстат предлагает три сценария: низкий, средний, высокий. Согласно низкому (худшему) сценарию, в 2018 г. численность населения в России составит 146,8 млн человек, а в 2036 упадет до 136 млн 730 тыс. Средний сценарий дает в 2018 г. практически тот же прогноз, что и низкий, но предсказывает сокращение числа россиян к 2036 г. только на один миллион - до 145 млн человек. Высокий прогноз полон оптимизма: почти 147 млн в 2018 г. и более 157 млн в 2036 это плюс почти десять миллионов. Кстати, новая концепция пространственного развития РФ планирует увеличение продолжительности жизни россиян до 80 лет.

Насколько это реально?

Одно из главных препятствий - «анклавизация» территорий, она возникает в условиях имущественного расслоения и роста миграции. Для устойчивого демографического развития России необходимо сократить социальное расслоение, добиться стабильного развития городов и сел на основе экономического роста и гарантий занятости.

«Прежде чем попытаться определить основные направления сбережения населения Российской Федерации, необходимо выделить и научно обосновать элементы (факторы), условия и предпосылки системного механизма (модели) сохранения и повышения конкурентоспособности экономики страны», - вступает в диалог доктор экономических наук, профессор В. Н. Лавров.

Мировой опыт последних двух веков свидетельствует о том, что главные, определяющие функции регулирования, планирования, стимулирования экономических процессов в стране реализовывать, то есть осуществлять, кроме государства, некому. Если исходить из предположения американских экономистов о том, что в любом государстве экономика включает минимум три сектора: частный, государственный и корпоративный, то следует сделать вывод о том, что никаких стопроцентно рыночных экономик и даже секторов не бывает в реалиях по существу. Поэтому экономику современного государства можно, на наш взгляд, представить как «трехсекторную модель смешанной экономики» (и наша - не исключение). Достаточно перечислить специфические функции государственного регулирования, чтобы понять, что они монопольно принадлежит только государству и никто другой (никакой другой субъект хозяйствования) - ни субъект частного сектора, ни субъект корпоративного сектора - должным образом их выполнить не смогут. Речь идет о следующих функциях государства в экономической политике: 1) стабилизация производства; 2) финансирование НТП; 3) дотация социально значимых отраслей; 4) выравнивание уровней экономического развития различных регионов; 5) государственная поддержка конкуренции; 6) стабилизация и оздоровление денежной системы; 7) преодоление чрезмерной имущественной дифференциации населения; 8) социальная эколого-экономическая защита малоимущих и среднего класса (малый и 
средний бизнес). От эффективного выполнения этих функций зависит качество экономического развития государства, его политического имиджа.

«Для меня, как экономиста, - заключает В. Н. Лавров, - перевейшей и важнейшей задачей является разработка, научное обоснование идеологических принципов, положений и футурологических идеологем, связанных с методами достижения справедливого распределения произведенных благ, отвечающих ментальным особенностям и чаяньям большинства российских граждан».

Обсуждение проблем «понимания России», заявленных в данной конференции, логично продолжилось выступлением доктора философских наук, профессора Ю. Г. Ершова. Он акцентировал внимание на современном толковании национальной идеи, ее сущностных признаках, связи с идеологией и конструктивных возможностях. Ю. Г. Ершов подчеркнул, что именно национальная идея выражает и отражает национальное самосознание, идентичность, связывающую как ряд поколений, так и отдельных личностей через символы и ценности национальной культуры.

В той мере, в какой национальная идея представляет систему ценностей, выступающей в качестве политического мировоззрения, имеющей силу веры, претендует на ориентации общества и государства, способность преодолевать кризисы и социальные аномии, она является идеологией.

Национальная идея включает в себя самые существенные черты различных видов исторической памяти: о происхождении и предках народов, их образе и уровне жизни, формах государственного устройства, истоках родного языка, эпосе, традициях и обычаях, моральных и социальных нормах, культурных обрядах прошлого и принятии религии, об исторически сложившихся формах общения с другими народами. Национальная идея формируется и прививается прежде всего в семье (внутрисемейные межпоколенческие социальные коммуникации), в школе, в поле общественного и государственного образовательного, воспитательного, пропагандистского информационного воздействия. Национальная идея формируется и закрепляется исторически, передается в поколениях, отражает оптимальную меру традиции и модернизации, находя современные формы своего воплощения, но не меняя своей сущности, своего глубинного содержания.

Участники круглого стола единодушно высказались о значимости и актуальности проекта «Учимся понимать Россию не только сердцем, но и умом», обозначив варианты междисциплинарного научного сотрудничества, конвергентных исследований, создания научных сообществ, в том числе с международным участием.
For citing: Zabara L.I.

The geopolitical image of Russia

in the modern media space

(international conference

«Learning to understand Russia:

political and mass media communication»,

10-14 December, Yekaterinburg) //

Socium i vlast' 2018. № 6 (74). P. 117-121.

UDC $327.2+366.63$

\section{THE GEOPOLITICAL IMAGE OF RUSSIA IN THE MODERN MEDIA SPACE (INTERNATIONAL CONFERENCE «LEARNING TO UNDERSTAND RUSSIA: POLITICAL AND MASS MEDIA COMMUNICATION", 10-14 December, Yekaterinburg)}

\section{Lyudmila I. Zabara,}

Ural State Pedagogical University, Associate Professor, Cand.Sc. (Philosophy), Russian Federation,

620017, Yekaterinburg, prospect Kosmonavtov, 26 E-mail:rni221@yandex.ru

\section{Abstract}

The paper is a review of the round-table meeting work on the topic "The geopolitical image of Russia", held in the framework of the International Scientific Conference on Political Communication "Learning to Understand Russia: Political and Mass Media Communication". The paper describes the content of the most significant reports and discussions, which reveal the features of internal and external factors forming the geopolitical image of Russia. There is a need for convergent researches, for creating scientific communities to study the presented topic more deeply and thoroughly.

Key concepts:

geopolitical image,

"globalization" of higher education,

demographic projection,

national idea,

historical memory. 